ISSN: $1412-8837$

\title{
ANALISIS PENDAPATAN DAN EFISIENSI USAHA DAGANG BUAH-BUAHAN DI KOTA BENGKULU (STUDI KASUS PEDAGANG MENETAP DAN SEMI MENETAP/MOBILE)
}

\section{INCOME AND BUSINESS EFFICIENCY ANALYSIS FRUITS TRADERS IN KOTA BENGKULU (A CASE STUDY OF STATIC AND MOBILE TRADERS)}

\author{
Asima M. Sidabutar, Nyayu Neti Arianti, dan Apri Andani \\ Jurusan Sosial Ekonomi Pertanian Fakultas Pertanian Universitas Bengkulu
}

\begin{abstract}
This research was undertaken in Kota Bengkulu Provinsi Bengkulu. There were fifty eight fruit traders were censused method. They devided in two based on their type of services: fourty three for static services and fifteen for mobile services. All of them were interviewed to obtain information about their reasons for selecting their services. Descriptive analysis, income and $R / C$ ratio are use in this research. The main reason to select static service is that they trade in local government licensed area. Second reason is that thier target customers and consumers often shop in traditional market and had medium income. While mobile traders, the easyness to find customers and consumers are the main reason and traders can move from one to another place. The static traders earned $\mathrm{Rp}$. 4.064.236,36 and mobile traders $\mathrm{Rp}$.5.007.664,29 per month. R/C Ratio of static is 1,11 and mobile 1,16. Both of them were efficient because R/C Ratio were higher than 1.
\end{abstract}

Keywords: fruit traders, income, business efficiency.

\section{PENDAHULUAN}

Buah memiliki nilai komersial yang cukup tinggi karena buah merupakan produk pertanian yang selalu dikonsumsi untuk mendapatkan sumber vitamin sesuai konsep pola makan sehat dan gizi berimbang. Konsumsi buah di Indonesia saat ini beragam dengan meningkatnya kesadaran masyarakat akan kebutuhan gizi yang sejalan dengan peningkatan pendidikan dan kesejahteraan masyarakat. Peningkatan konsumsi buah-buahan yang beragam ini merupakan peluang besar bagi pedagang pengecer buah di pasar tradisional. Pasar tradisional merupakan salah satu indikator paling nyata dalam kegiatan ekonomi masyarakat di suatu wilayah. 
Saat ini pasar tradisional sudah berdampingan dengan pasar modern yang menyediakan berbagai kebutuhan pokok sama halnya dengan pasar tradisional. Pesatnya pembangunan pasar modern berdampak terhadap keberadaan pasar tradisional. Hampir semua produk yang dijual di pasar tradisional seluruhnya dapat ditemui di pasar modern, seperti Giant dan Hypermart. Semenjak kehadiran pasar modern tersebut, keuntungan pasar tradisional di kota Bengkulu diduga menurun.

Pedagang di pasar tradisional yang mengalami dampak langsung dari keberadaan pasar modern adalah pedagang yang menjual produk yang sama dengan yang dijual di kedua tempat tersebut. Seperti pedagang daging, ayam, ikan, sayur-sayuran, buah-buahan, dan lain lain. Dampak yang paling dirasakan pedagang adalah tingginya persaingan untuk memperoleh pembeli yang dapat mempengaruhi tingkat keuntungan pedagang. Keunggulan pasar modern atas pasar tradisional adalah bahwa mereka dapat menjual produk yang relatif sama dengan harga yang lebih murah, ditambah dengan kenyamanan berbelanja dan beragam pilihan cara pembayaran.

Meskipun dengan kondisi yang tidak menguntungkan, karena pasar modern lebih mampu menarik perhatian konsumen dengan suasana berbelanja yang menyenangkan melalui desain eksterior dan interiornya, ternyata masih banyak ditemukan pedagang pengecer buah yang menjual dagangannya di Kota Bengkulu. Pedagang buah tersebut memilih sifat layanan menetap dan semi menetap atau mobile untuk menjual barang dagangannya. Pedagang menetap yang berada di pasar tradisional memilih sarana kios dengan alasan bahwa kios tempat mereka berdagang berada pada kawasan yang merupakan pusat kegiatan perekonomian kota sehingga sering dikunjungi dalam jumlah yang banyak. Sedangkan pedagang semi menetap / mobile yang berada di pinggiran jalan raya mengaku bahwa dengan menggunakan mobil pick-up maka hal ini dapat memudahkan pengunjung untuk membeli buah tanpa meninggalkan kendaraannya jauh dari tempat ia berbelanja selain itu pedagang juga lebih mudah menjajakan barang dagangannya.

Hasil wawancara awal yang dilakukan terhadap beberapa pedagang buah menyatakan bahwa pedagang terkadang sulit untuk meningkatkan pendapatannya. Karena beberapa pedagang buah masih harus mengeluarkan biaya yang cukup besar untuk menyewa mobil dan kios yang ia gunakan. Selain itu, tingginya harga bahan bakar minyak dan besarnya biaya transportasi untuk pengangkutan buah dari pemasok sampai ke tempat berdagang sangat berpengaruh pada besarnya tingkat pendapatan yang dihasilkan oleh pedagang. Oleh karena itu, perlu dilakukan penelitian untuk menganalisis efisiensi usaha dagang buah antara pedagang menetap dengan pedagang semi menetap dengan mengukur tingkat pendapatan pedagang pengecer buah sehingga dapat dilihat apakah usaha dagang pengecer buah efisien atau tidak.

Berdasarkan permasalahan yang ada, maka tujuan dari penelitian ini adalah: (a) Mengetahui apa saja yang menjadi alasan pedagang memilih sifat layanan menetap dan semi menetap/mobile dalam menjual buah-buahan, (b) 
Mengetahui besarnya pendapatan, dan (c) mengetahui tingkat efisiensi usaha dagang buah pedagang menetap dan semi menetap/mobile di Kota Bengkulu.

\section{METODE PENELITIAN}

\section{Metode Penentuan Lokasi Penelitian}

Lokasi penelitian ini dilakukan di Kota Bengkulu. Penentuan lokasi penelitian ditentukan secara sengaja (purposive) dengan pertimbangan terdapat usaha dagang buah-buahan dengan perbedaan pemilihan sifat layanan dan sarana fisik. Di pasar tradisional mayoritas pedagang memilih sifat layanan menetap dengan menggunakan sarana fisik kios sedangkan pedagang semi menetap atau mobile yang menggunakan sarana fisik mobil pick-up banyak ditemukan di pinggiran jalan raya.

\section{Metode Penentuan Responden}

Populasi yang menjadi target penelitian adalah pedagang buah-buahan menetap dan semi menetap yang ada di Kota Bengkulu. Pedagang buah-buahan menetap ada 43 dan semi menetap (mobile) ada 15, seperti yang disajikan pada Tabel 1.

Tabel 1. Populasi pedagang buah-buahan menetap dan semi menetap di Kota Bengkulu

\begin{tabular}{llcc}
\hline No. & \multicolumn{1}{c}{ Kecamatan } & Menetap (Kios) & $\begin{array}{c}\text { Semi Menetap } \\
\text { (Mobil Pick-U } \mathbf{p})\end{array}$ \\
\hline 1. & Gading Cempaka & 20 & - \\
2. & Muara Bangka Hulu & 3 & - \\
3. & Ratu Agung & 7 & - \\
4. & Ratu Samban & 10 & 9 \\
5. & Sungai Serut & 3 & 1 \\
6. & Teluk Segara & - & 5 \\
\hline & Jumlah & $\mathbf{4 3}$ & $\mathbf{1 5}$ \\
\hline
\end{tabular}

Penentuan sampel dilakukan dengan metode sensus. Menurut Arikunto (2002) dalam Desi (2005) yang menyatakan bahwa, apabila jumlah populasi kurang dari 100 lebih baik diambil semua. Karena jumlah seluruh populasi ada 58 pedagang, maka semuanya digunakan sebagai sampel dalam penelitian ini.

\section{Metode Pengumpulan Data}

Data yang digunakan dalam penelitian ini berupa data primer dan data sekunder. Data primer adalah data yang diperoleh dari responden melalui wawancara langsung dengan responden dengan panduan kuisioner. Data yang diperoleh dari responden adalah data mingguan yang ditelusuri setiap minggu 
dalam 4 minggu waktu penelitian yang kemudian dirangkum menjadi data bulanan. Sedangkan data sekunder diperoleh dari data yang berasal dari instansi yang terkait seperti dinas pengelola pasar dan Badan Pusat Statistik untuk melengkapi data primer yang diperoleh sehingga dapat dibuat analisa yang lebih lengkap dan bersifat menyeluruh tentang masalah yang diteliti.

\section{Metode Analisis Data}

Analisis deskriptif digunakan untuk mendiskripsikan apa saja yang menjadi alasan pedagang dalam memilih sifat layanan menetap dan semi menetap/mobile dalam menjual buah-buahan. Untuk menghitung pendapatan usaha dagang buah dihitung dengan rumus: pendapatan adalah penerimaan usaha dikurangi total biaya usaha.

Penerimaan adalah hasil parkalian antara harga jual dengan jumlah buah yang terjual pada semua jenis buah dalam setiap bulannya.

$$
\mathrm{TR}=\mathrm{P} \times \mathrm{Q}
$$

(Suratiyah, 2006)

dimana TR adalah Total penerimaan dari semua jenis buah (Rp/Bulan), $\mathrm{P}$ adalah Harga jual dari semua jenis buah $(\mathrm{Rp} / \mathrm{Kg}), \mathrm{Q}$ adalah Jumlah yang terjual dari semua jenis buah $(\mathrm{Kg} /$ Bulan). Sementara itu, pendapat dihitung dengan rumus sebagai berikut:

$$
\mathrm{P}=\mathrm{TR}-\mathrm{TC}
$$

dimana $\mathrm{P}$ adalah Total pendapatan dari semua jenis buah (Rp/Bulan), TR adalah Total Penerimaan dari semua jenis buah (Rp/Bulan), TC adalah total biaya dari semua jenis buah ( $\mathrm{Rp} /$ Bulan), dihitung dengan rumus:

$$
\mathrm{TC}=\mathrm{TFC}+\mathrm{TVC}
$$

dimana TFC adalah total biaya tetap dari semua jenis buah (Rp/Bulan), dan TVCadalah total biaya variabel dari semua jenis buah (Rp/Bulan)

Untuk mengetahui tingkat efisiensi usaha dagang buah digunakan rumus:

$$
R / C \text { rasio }=\frac{\text { TotalPenerimaan }}{\text { TotalBiaya }}=\frac{T R}{T C} \quad \text { (Soekartawi, 1995) }
$$

dengan kriteria pengambilan keputusan: (a) Jika $R / C$ Ratio $>1$, maka usaha tersebut efisien, (b) Jika $R / C$ Ratio $=1$, maka usaha tersebut berada pada titik impas, dan (c) Jika $R / C$ Ratio < 1, maka usaha tersebut tidak efisien

\section{HASIL DAN PEMBAHASAN}

\section{Karakteristik Pedagang Buah-buahan}

Karakteristik dan identitas responden yang meliputi umur, pendidikan, jumlah tanggungan keluarga, lama berdagang (tahun) dan lama berdagang (jam/hari), dapat dilihat pada Tabel 2. 
Tabel 2. Karakteristik Responden

\begin{tabular}{|c|c|c|c|c|c|c|c|}
\hline \multirow[b]{2}{*}{ No } & \multirow[b]{2}{*}{ Uraian } & \multicolumn{3}{|c|}{ Menetap } & \multicolumn{3}{|c|}{ Semi Menetap/Mobile } \\
\hline & & Jml & $\%$ & $\begin{array}{c}\text { Rata-rata } \\
\text { keseluruhan }\end{array}$ & Jml & $\%$ & $\begin{array}{c}\text { Rata-rata } \\
\text { keseluruhan }\end{array}$ \\
\hline \multirow[t]{5}{*}{1} & Umur (tahun) & & & \multirow{5}{*}{41,23} & & & \multirow{5}{*}{41,13} \\
\hline & $20-30$ & 3 & 6,98 & & 7 & 46,67 & \\
\hline & $31-40$ & 13 & 30,23 & & 8 & 53,33 & \\
\hline & $41-50$ & 27 & 62,79 & & & & \\
\hline & Total & 43 & 100,00 & & 15 & 100,00 & \\
\hline \multirow[t]{5}{*}{2} & \multicolumn{6}{|c|}{ Pendidikan formal (tahun) } & \multirow{5}{*}{8,60} \\
\hline & $\leq 6$ & 9 & 20,93 & \multirow{4}{*}{9,49} & 5 & 33,33 & \\
\hline & $7-9$ & 21 & 48,84 & & 7 & 46,67 & \\
\hline & $>9$ & 13 & 30,23 & & 3 & 20,00 & \\
\hline & Total & 43 & 100,00 & & 15 & 100,00 & \\
\hline \multirow[t]{4}{*}{3} & Jumlah tanggu & gan kel & $\operatorname{arga}($ or & \multirow{4}{*}{5,09} & & & \multirow{4}{*}{4,87} \\
\hline & $1-5$ & 28 & 65,12 & & 11 & 73,33 & \\
\hline & $6-10$ & 15 & 34,88 & & 4 & 26,67 & \\
\hline & Total & 43 & 100,00 & & 15 & 100,00 & \\
\hline \multirow[t]{7}{*}{4} & \multicolumn{6}{|c|}{ Pengalaman berdagang (tahun) } & \multirow{7}{*}{9,73} \\
\hline & $1-5$ & 2 & 4,65 & & & & \\
\hline & $6-10$ & 16 & 37,21 & & 3 & 20,00 & \\
\hline & $11-15$ & 22 & 51,16 & 12,37 & 9 & 60,00 & \\
\hline & $16-20$ & 2 & 4,65 & & 3 & 20,00 & \\
\hline & $21-25$ & 1 & 2,33 & & & & \\
\hline & Total & 43 & 100,00 & & 15 & 100,00 & \\
\hline \multirow[t]{4}{*}{5} & Lama berdaga & (jam/ & ari) & \multirow{4}{*}{11,37} & & & \multirow{4}{*}{10,67} \\
\hline & $5-10$ & 14 & 32,56 & & 10 & 66,67 & \\
\hline & $11-15$ & 29 & 67,44 & & 5 & 33,33 & \\
\hline & Total & 43 & 100,00 & & 15 & 100,00 & \\
\hline
\end{tabular}

Sumber: Data primer diolah, 2012

\section{Alasan Pedagang Memilih Sifat Layanan}

Pemilihan sifat layanan menetap dan semi menetap/mobile oleh pedagang buah-buahan adalah karena alasan-alasan yang berbeda dari berbagai faktor berikut ini (Tabel 3).

Pedagang menetap mengaku bahwa masyarakat yang memiliki tingkat pendapatan menengah ke bawah menjadi target mereka, tidak heran mengapa pedagang menetap banyak ditemui di pasar tradisional seperti di Pasar Minggu dan Pasar Panorama. Sedangkan pedagang semi menetap/mobile mengaku bahwa kawasan masyarakat populasi pekerja profesi dan yang memiliki tingkat pendidikan yang tinggi menjadi target mereka, sehingga pedagang semi menetap/mobile banyak ditemui di kawasan perkantoran. 
Tabel 3. Alasan Pedagang Memilih Sifat Layanan

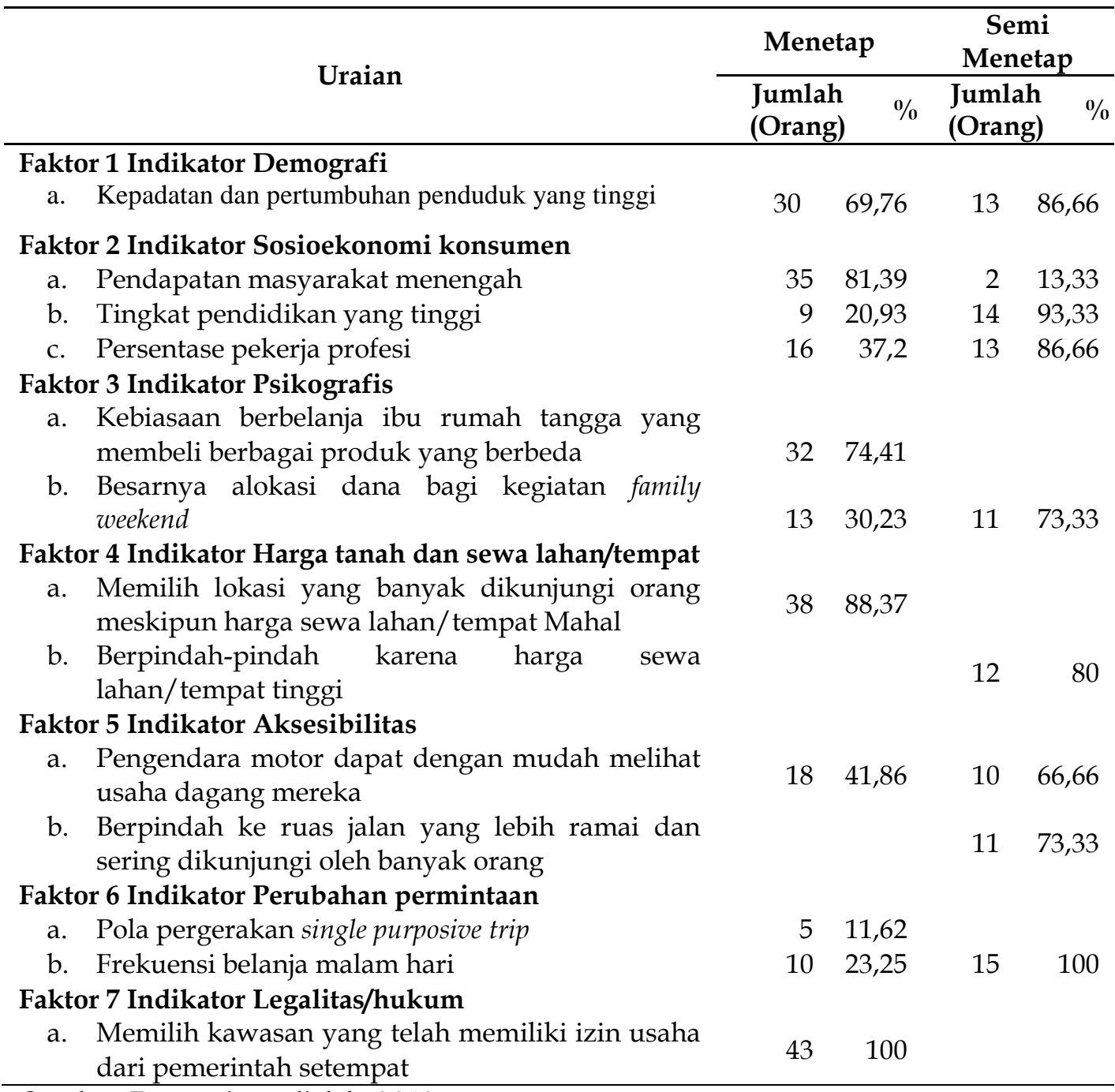

Sumber: Data primer diolah, 2012

\section{Biaya Usaha Dagang Buah-buahan}

Pedagang buah menetap dan semi menetap/mobile mengeluarkan jenis biaya yang hampir sama, namun ada beberapa biaya yang dikeluarkan pedagang menetap tidak dikeluarkan oleh pedagang semi menetap/mobile demikian juga sebaliknya. Untuk lebih jelasnya, struktur biaya usaha dagang buah-buahan pada pedagang menetap dan semi menetap/mobile dapat dilihat pada Tabel 4 berikut.

Biaya variabel pembelian buah untuk pedagang menetap adalah sebesar Rp. 31.014.626,87/bulan. Pedagang semi menetap/mobile mengeluarkan biaya variabel pembelian buah sebesar Rp. 27.556.496,03/bulan. Mereka jauh lebih 
kecil mengeluarkan biaya variable pembelian buah bila dibandingkan dengan pedagang menetap.

Tabel 4. Rata-rata Biaya Usaha Dagang Buah-buahan

\begin{tabular}{|c|c|c|c|c|}
\hline \multirow{2}{*}{ Uraian } & \multicolumn{2}{|l|}{ Menetap } & \multicolumn{2}{|c|}{ Semi Menetap/Mobile } \\
\hline & Rp/Bulan & $\%$ & Rp/Bulan & $\%$ \\
\hline \multicolumn{5}{|l|}{ Biaya Tetap } \\
\hline Retribusi & $43.478,26$ & 12,04 & & \\
\hline Pajak Kendaraan & & & $426.666,67$ & 50,14 \\
\hline Kios/Tempat & $194.500,00$ & 53,86 & & \\
\hline Jaga Malam & $51.166,67$ & 14,17 & & \\
\hline Penyusutan Alat & $71.955,65$ & 19,93 & $424.309,52$ & 49,86 \\
\hline Jumlah Biaya Tetap (A) & $361.100,58$ & 100,00 & $850.976,19$ & 100,00 \\
\hline \multicolumn{5}{|l|}{ Biaya Variabel } \\
\hline Listrik & $36.558,14$ & 0,10 & $55.666,67$ & 0,18 \\
\hline Bahan Bakar & & & $96.333,33$ & 0,31 \\
\hline Angkut Buah & $888.372,09$ & 2,45 & $333.333,33$ & 1,06 \\
\hline Kantong Plastik: & & & & \\
\hline a. $1 \mathrm{Kg}$ & $65.546,51$ & 0,18 & $43.666,67$ & 0,14 \\
\hline b. $3 \mathrm{Kg}$ & $101.616,28$ & 0,28 & $51.533,33$ & 0,16 \\
\hline c. $5 \mathrm{Kg}$ & $56.837,21$ & 0,16 & $32.866,67$ & 0,10 \\
\hline Jaring Plastik & $207.093,02$ & 0,57 & $96.333,33$ & 0,31 \\
\hline Tenaga Kerja: & & & & \\
\hline a. Dalam Keluarga & $675.581,40$ & 1,86 & $646.666,67$ & 2,06 \\
\hline b. Luar Keluarga & $650.000,00$ & 1,79 & & \\
\hline Pemeliharaan Mobil & & & $95.000,00$ & 0,30 \\
\hline Pembelian Buah & $31.014 .626,87$ & 85,46 & $27.556 .496,03$ & 87,83 \\
\hline Penyusutan Buah & $2.596 .779,52$ & 7,16 & $2.367 .328,57$ & 7,55 \\
\hline Jumlah Biaya Variabel (B) & 36.293.011,04 & 100,00 & $31.375 .224,60$ & 100,00 \\
\hline Total Biaya $(\mathrm{C})=(\mathrm{A})+(\mathrm{B})$ & 36.654.111,62 & & $32.226 .200,79$ & \\
\hline
\end{tabular}

Sumber: Data primer diolah, 2012

Rata-rata pedagang buah menetap dan semi menetap/mobile melakukan pembelian buah-buahan satu kali dalam seminggu atau empat kali dalam sebulan. Hal ini mereka lakukan karena mengingat kondisi buah yang mudah busuk dan tidak dapat disimpan dalam waktu yang lama sehingga untuk menghindarinya, mereka melakukan pembelian sekali dalam seminggu. Volume pembelian dan harga beli serta harga jual buah rata-rata setiap minggu dapat dilihat pada Tabel 5 dan Tabel 6.

\section{Penerimaan, Pendapatan dan Efisiensi Usaha}

Sebenarnya tujuan dari setiap pedagang adalah untuk mendapatkan pendapatan atau keuntungan yang maksimal dari usaha yang dijalankannya. Pedagang buah-buahan selalu berusaha untuk mendapatkan keuntungan yang 
maksimal hal ini dapat terlihat dari semangat dan motivasi mereka dalam menekuni usaha berjualan buah-buahan yang ditekuninya setiap hari. Pendapatan pedagang buah-buahan diperoleh dengan mengurangkan penerimaan dengan total biaya yang dikeluarkan, seperti tertera pada Tabel 7.

Tabel 5. Rata-rata Volume Pembelian dan Harga Beli Buah-buahan/ minggu

\begin{tabular}{|c|c|c|c|c|c|c|}
\hline \multirow{2}{*}{ Jenis Buah } & \multicolumn{3}{|c|}{ Menetap } & \multicolumn{3}{|c|}{ Semi Menetap/Mobile } \\
\hline & $\mathrm{Kg}$ & $\mathrm{Rp} / \mathrm{Kg}$ & Nilai (Rp) & $\mathrm{Kg}$ & $\mathrm{Rp} / \mathrm{Kg}$ & Nilai (Rp) \\
\hline \multicolumn{7}{|l|}{ 1. Apel Merah } \\
\hline Besar & 32,94 & $16.573,53$ & $545.951,57$ & 26,36 & $16.136,36$ & $425.413,12$ \\
\hline Kecil & 10,33 & $15.444,44$ & $159.592,54$ & 20,00 & $15.000,00$ & $300.000,00$ \\
\hline 2. Apel Fuji & 30,93 & $13.433,77$ & $415.543,59$ & 31,00 & $14.305,56$ & $443.472,36$ \\
\hline \multicolumn{7}{|l|}{ 3. Apel Hijau } \\
\hline Perancis & 7,75 & $16.979,17$ & $131.588,57$ & 26,67 & $16.333,33$ & $435.555,47$ \\
\hline Malang & 16,90 & $10.500,00$ & $17.7450,00$ & 35,00 & $10.333,33$ & $361.666,55$ \\
\hline \multicolumn{7}{|l|}{ 4. Pir } \\
\hline Madu & 30,59 & $6.294,12$ & $192.526,02$ & 44,06 & $9.426,09$ & $415.322,83$ \\
\hline Yali & 18,78 & $15.000,00$ & $281.666,67$ & 22,50 & $15.250,00$ & $343.125,00$ \\
\hline 5. Anggur & 8,02 & $26.793,02$ & $214.967,25$ & 8,73 & $26.746,67$ & $233.587,59$ \\
\hline \multicolumn{7}{|l|}{ 6. Jeruk } \\
\hline Lebong & 67,5 & $21.750,00$ & $1.468 .125,00$ & 46,67 & $22.333,33$ & $1.042 .222,07$ \\
\hline Berastagi & 79,43 & $10.300,00$ & $818.114,28$ & 59,00 & $10.000,00$ & $590.000,00$ \\
\hline Pon Kan & 50,58 & $8.930,23$ & $451.703,49$ & 58,33 & $8.666,67$ & $505.555,75$ \\
\hline Sunkist & 33,33 & $20.000,00$ & $666.666,66$ & 20,00 & $20.000,00$ & $400.000,00$ \\
\hline 7. Lengkeng & 39,44 & $22.301,95$ & $879.480,03$ & 46,67 & $22.000,00$ & $1.026 .666,66$ \\
\hline \multicolumn{7}{|l|}{ 8. Melon } \\
\hline Biasa & 49,00 & $8.045,81$ & $394.281,1$ & 40,00 & $7.666,67$ & $306.666,80$ \\
\hline Orange & 38,18 & $8.000,00$ & $305.454,54$ & 25,00 & $8.000,00$ & $200.000,00$ \\
\hline 9. Salak Pondoh & 89,88 & $6.976,74$ & $627.095,35$ & 79,33 & $6.866,67$ & $544.755,82$ \\
\hline 10. Semangka & 85,00 & $8.041,67$ & $683.541,95$ & 59,00 & $8.000,00$ & $472.000,00$ \\
\hline 11. Mangga & 59,17 & $15.791,67$ & $934.340,48$ & 29,5 & $15.000,00$ & $442.500,00$ \\
\hline Jumlah & 747,75 & & 9348089,09 & 677,82 & & $8.488 .510,02$ \\
\hline Max & 89,88 & $26.793,02$ & $146.8125,00$ & 79,33 & $26.746,67$ & 1.042.222,07 \\
\hline Min & 7,75 & $6.294,12$ & $131.588,57$ & 8,73 & $6.866,67$ & $200.000,00$ \\
\hline
\end{tabular}

Sumber: Data primer diolah, 2012 
Tabel 6. Rata-rata Volume Penjualan dan Harga Jual Buah-buahan Perminggu

\begin{tabular}{|c|c|c|c|c|c|c|}
\hline \multirow{2}{*}{ Jenis Buah } & \multicolumn{3}{|c|}{ Menetap } & \multicolumn{3}{|c|}{ Semi Menetap/Mobile } \\
\hline & Kg & $\mathrm{Rp} / \mathrm{Kg}$ & Nilai (Rp) & $\mathrm{Kg}$ & $\mathrm{Rp} / \mathrm{Kg}$ & Nilai (Rp) \\
\hline \multicolumn{7}{|l|}{ 1. Apel Merah } \\
\hline Besar & 30,53 & $24.117,65$ & $736.297,57$ & 24,64 & $23.409,09$ & $576.714,88$ \\
\hline Kecil & 9,22 & $25.000,00$ & $230.555,56$ & 18,50 & $22.500,00$ & $416.250,00$ \\
\hline 2. Apel Fuji & 29,81 & $19.193,63$ & $572.179,78$ & 29,59 & $21.555,56$ & $637.804,95$ \\
\hline \multicolumn{7}{|l|}{ 3. Apel Hijau } \\
\hline Perancis & 7,08 & $25.000,00$ & $177.083,33$ & 24,67 & $25.000,00$ & $616.666,68$ \\
\hline Malang & 15,70 & $15.000,00$ & $235.500,00$ & 31,83 & $16.500,00$ & $525.249,99$ \\
\hline \multicolumn{7}{|l|}{ 4. Pir } \\
\hline Madu & 28,94 & $14.352,94$ & 91,00 & 32,12 & 12.9 & $415.791,26$ \\
\hline Yali & 18,22 & $23.666,67$ & 431. & 21,25 & $22.750,00$ & $483.437,50$ \\
\hline 5. Anggur & 7,49 & $49.186,05$ & $368.323,42$ & 7,97 & $50.000,00$ & $398.333,33$ \\
\hline \multicolumn{7}{|l|}{ 6. Jeruk } \\
\hline Lebong & 61,25 & $26.750,00$ & 1.638 & 44,00 & $26.666,67$ & $1.173 .333,30$ \\
\hline Berastagi & 73,16 & $14.528,57$ & $1.062 .868,80$ & 54,23 & $14.600,00$ & $791.806,67$ \\
\hline Pon Kan & 46,47 & $13.627,91$ & $633.222,28$ & 51,97 & $14.066,67$ & $730.997,79$ \\
\hline Sunkist & 32,33 & $24.000,00$ & 775 & 10,00 & $25.000,00$ & $250.000,00$ \\
\hline 7. Lengkeng & 37,76 & $28.940,11$ & $1.092 .725,50$ & 43,40 & $28.900,00$ & $1.254 .260,00$ \\
\hline \multicolumn{7}{|l|}{ 8. Melon } \\
\hline Biasa & 46,58 & 11.96 & 557 & 36,60 & 11.2 & $410.530,01$ \\
\hline Orange & 36,36 & $11.272,73$ & 7,34 & 23,83 & $11.333,33$ & $270.111,10$ \\
\hline 9. Salak Pondoh & 81,81 & $09.837,21$ & $804.821,00$ & 73,83 & $09.866,67$ & $728.488,91$ \\
\hline 10. Semangka & 82,29 & $10.833,33$ & $891.493,03$ & 56,30 & $11.200,00$ & $630.560,00$ \\
\hline 11. Mangga & 56,58 & $19.500,00$ & $1.103 .375,00$ & 27,80 & $19.600,00$ & $544.880,00$ \\
\hline Jumlah & 701,59 & & 12136963,45 & 612,53 & & 10855216,37 \\
\hline $\operatorname{Max}$ & 82,29 & $49.186,05$ & $1.638 .437,50$ & 73,83 & $50.000,00$ & $1.254 .260,00$ \\
\hline Min & 7,08 & $09.837,21$ & $177.083,33$ & 7,97 & $09.866,67$ & $250.000,00$ \\
\hline
\end{tabular}

Sumber: Data primer diolah, 2012

Tabel 7. Rata-rata Penerimaan, Pendapatan dan R/C Ratio Usaha Dagang Buah-buahan

\begin{tabular}{lrr}
\hline \multicolumn{1}{c}{ Uraian } & \multicolumn{1}{c}{ Menetap } & \multicolumn{1}{c}{$\begin{array}{c}\text { Semi } \\
\text { Menetap/Mobile } \\
\text { (Rp/Bulan) }\end{array}$} \\
\hline Penerimaan (A) & (Rp/Bulan) & $37.233 .865,08$ \\
Total Biaya (B) & $40.718 .347,98$ & $32.226 .200,79$ \\
Pendapatan = (A) - (B) & $36.654 .111,62$ & $5.007 .664,29$ \\
R/C Ratio = (A) : (B) & $4.064 .236,36$ & 1,16 \\
\hline
\end{tabular}

Sumber: Data primer diolah, 2012 
Berdasarkan Tabel 7 di atas dapat dilihat bahwa penerimaan pedagang menetap rata-rata adalah sebesar Rp. 40.718.347,98/bulan. Penerimaan pedagang menetap ini jauh lebih besar bila dibandingkan dengan pedagang semi menetap/mobile yang memiliki penerimaan rata-rata sebesar Rp. 37.233.865,08/bulan. Untuk pendapatan pedagang semi menetap/mobile sedikit lebih besar yaitu Rp. 5.007.664,29/bulan bila dibandingkan dengan pendapatan pedagang menetap yang rata-rata memiliki pendapatan sebesar Rp. 4.064.236,36/bulan. Dari hasil wawancara dengan pedagang membuktikan bahwa pendapatan yang mereka peroleh dari hasil penjualan buah-buahan dapat mencukupi kebutuhan hidup keluarga mereka. Hal ini sejalan dengan penelitian Purba (2004) yang menyatakan bahwa pendapatan pedagang pengecer buah jeruk berastagi di Kota Bengkulu (Rp. 1. 405.552/bulan) bisa memenuhi kebutuhan keluarga pedagang pengecer tersebut.

Usaha dagang buah-buahan menetap maupun semi menetap/mobile memiliki tingkat efisiensi usaha lebih dari satu, artinya kedua jenis layanan ini sudah efisien atau menguntungkan, dimana yang menetap sebesar 1,11 dan semi menetap/mobile sebesar 1,16.

Besarnya nilai R/C Ratio yang diperoleh pedagang semi menetap/mobile dapat disebabkan oleh beberapa hal. Salah satunya adalah karena jumlah volume penjualanan buah oleh pedagang semi menetap/mobile lebih besar dari pedagang menetap. Volume penjualan buah semi menetap/mobile lebih besar karena volume pembelian mereka juga lebih besar dari volume pembelian pedagang menetap. Sudah sewajarnya pedagang semi / mobile memperoleh nilai efisiensi lebih besar karena penerimaan yang mereka peroleh juga lebih besar dari penerimaan yang diperoleh pedagang menetap.

\section{SIMPULAN DAN SARAN}

\section{Simpulan}

1. Alasan pedagang menetap adalah kawasan tempat mereka berdagang telah memiliki izin usaha dari pemerintah daerah setempat dan konsumen yang memiliki tingkat pendapatan menengah menjadi target mereka. Sedangkan alasan pedagang semi menetap/mobile adalah mereka akan mudah mendatangi lokasi/tempat konsumen berada.

2. Pendapatan yang diperoleh oleh pedagang semi menetap/mobile adalah Rp. 5.007.664,29/bulan. Pendapatan ini lebih tinggi daripada pendapatan pedagang menetap yang sebesar Rp. 4.064.236,36/bulan.

3. Usaha dagang buah-buahan menetap maupun semi menetap/mobile memiliki tingkat efisiensi usaha lebih dari satu. Artinya kedua jenis layanan ini sudah efisien atau menguntungkan, di mana yang menetap sebesar 1,11 dan semi menetap/mobile sebesar 1,16. 


\section{Saran}

Usaha dagang yang dilakukan kedua jenis pedagang adalah menguntungkan, namun pedagang semi menetap/mobile memiliki nilai pendapatan yang lebih besar dan lebih efisien. Oleh karena itu, sebaiknya pedagang harus mempertimbangkan sifat layanan seperti apa yang harus mereka gunakan agar usaha dagang mereka bisa lebih efisien.

\section{DAFTAR PUSTAKA}

Desi. 2005. Analisis Pendapatan Pedagang Sembako di Pasar Minggu Sehubungan dengan Mulai Dibangunnya Pasar Modern Mega Mall di Kota Bengkulu. Skripsi. Fakultas Ekonomi. Univesitas Bengkulu.

Soekartawi. 1995. Analisis Usahatani. Jakarta: Penebar Swadaya.

Suratiyah. 2006. Ilmu Usahatani. Jakarta: Penebar Swadaya. 